Total number of pages: 28

Total number of tables: 2

Total number of figures: 8

\title{
Apparent mass of the human body in the vertical direction: Effect of a footrest and a steering wheel
}

\author{
M.G.R. Toward, M.J. Griffin \\ Human Factors Research Unit, Institute of Sound and Vibration Research, \\ University of Southampton, Southampton, SO17 1BJ, England
}

Correspondence address:

Professor Michael J. Griffin

Human Factors Research Unit

Institute of Sound and Vibration Research

University of Southampton

Southampton SO17 1BJ

England

Telephone: (+44) 02380592277

Facsimile: (+44) 02380592927

e-mail: M.J.Griffin@soton.ac.uk 


\section{Abstract}

The apparent mass of the seated human body influences the vibration transmitted through a car seat. The apparent mass of the body is known to be influenced by sitting posture but the influence of the position of the hands and the feet is not well understood. This study was designed to quantify the influence of steering wheel location and the position of a footrest on the vertical apparent mass of the human body. The influences of the forces applied by the hands to a steering wheel and by the feet to a footrest were also investigated. Twelve subjects were exposed to whole-body vertical random vibration $\left(1.0 \mathrm{~ms}^{-2}\right.$ r.m.s over the frequency range 0.13 to $40.0 \mathrm{~Hz}$ ) while supported by a rigid seat with a backrest reclined to $15^{\circ}$. The apparent mass of the body was measured with five horizontal positions and three vertical positions of a steering wheel and also with hands in the lap, and with five horizontal positions of a footrest. The influence of five forward forces $(0,50,100,150,200 \mathrm{~N})$ applied separately to the 'steering wheel' and the footrest were also investigated as well as a 'no backrest' condition. With their hands in their laps, subjects exhibited a resonance around $6.7 \mathrm{~Hz}$, compared to $4.8 \mathrm{~Hz}$ when sitting upright with no backrest. In the same posture holding a steering wheel, the mass supported on the seat surface decreased and there was an additional resonance at $4 \mathrm{~Hz}$. Moving the steering wheel away from the body reduced the apparent mass at the primary resonance frequency and increased the apparent mass around the $4 \mathrm{~Hz}$ resonance. As the feet moved forward, the mass supported on the seat surface decreased, indicating that the backrest and footrest supported a greater proportion of the subject weight. Applying force to either the steering wheel or the footrest reduced the apparent mass at resonance and decreased the mass supported on the seat surface. It is concluded that the positions and contact conditions of the hands and the feet affect the biodynamic response of the body in a car driving posture. As the biodynamic response influences the vibration transmitted through seats, these factors should be considered in dynamic models of vehicle seating.

Keywords: apparent mass; biodynamics; seats; whole-body vibration; posture; force 


\section{Introduction}

Vehicle seats amplify vibration at some frequencies while attenuating vibration at other frequencies. The seat and the human body form a coupled system so that vibration transmitted through a seat is dependent not only on the dynamic properties of the seat [1] but also on the dynamic response of the body [2]. Understanding of the dynamic response of the human body has been used to develop mechanical models (i.e., anthropodynamic dummies) to replace human subjects in seat testing and also to develop mathematical models that predict seat transmissibility. The dynamic models of the body have been based on experimental data obtained with subjects sitting with their lower legs vertical and their hands in their laps with no backrest, or supported by a rigid flat vertical backrest. In vehicles, drivers and passengers are supported by reclined compliant backrests, seat pans are inclined, and the legs may be extended forward. The operation of steering wheels and pedals results in drivers having different postures from passengers. The influence of such variations in the position of the hands and the feet on the apparent mass of the body has received little attention.

Changes in the apparent mass of the body due to changes in posture may be expected due to variations in either the geometry of the body or the tension in muscles that support the body. Decreases in the frequency and magnitude of the principal vertical resonance around $5 \mathrm{~Hz}$ have been reported when subjects adopt slouched as opposed to erect postures (e.g. [2, 3, 4]). Increases in the frequency of the principal resonance have been reported when subjects tense muscles in the upper-body during vibration [2]. The apparent mass of the body is non-linear with vibration magnitude, with the resonance frequency decreasing with increasing magnitude [5]. Matsumoto and Griffin [6] showed that this non-linearity depended on muscle tension in the abdomen and, particularly, the buttocks, with non-linear characteristics less clear in tensed postures.

Factors influencing the apparent mass of a seated person include seat height [7], foot position [8] and, to a lesser extent, seat pan inclination [9, 10]. A seat backrest can alter body posture and the distribution of the forces supporting the body mass over seat surfaces. Supporting the 
back by an upright backrest decreases the apparent mass at resonance and the proportion of the body mass supported on the seat surface, but increases the resonance frequency [11]. Inclining a rigid backrest decreases the apparent mass at resonance and also the static mass supported on the seat surface, but increases the resonance frequency, although inclining a compliant backrest reduces the resonance frequency of the apparent mass [11]. Raising the height of a seat pan relative to the feet increases the apparent mass at resonance, due to more mass being supported on the seat surface $[9,12]$. A slight increase in the apparent mass at resonance has been observed if the feet are moved forward, possibly as a result of more mass being supported on the seat surface, however only a small range of foot movement $(150 \mathrm{~mm})$ has been investigated [8].

Rakheja et al. found apparent mass resonances between 6.5 and $8.6 \mathrm{~Hz}$ for subjects in car driving postures [8], compared to 4.5 to $5.0 \mathrm{~Hz}$ in previous studies with subjects sitting upright with no backrest support [2]. When subjects moved their hands from their laps to a steering wheel, both the apparent mass at resonance and the resonance frequency decreased and a second resonance became more pronounced in some subjects. Similarly, the resonance frequency and the apparent mass measured in a direction normal to a reclined backrest reduced when subjects exposed to vertical vibration held a steering wheel [13].

In studies of the transmission of vibration from a rigid seat to points on the body, the fore-andaft position of the seat relative to controls, and therefore the arm and leg angles, affected the movement of the upper-arm, lower-arm, shin and thigh [14]. The transmissibility at resonance to the upper-arm increased as the elbow angle increased from $90^{\circ}$ to $180^{\circ}$, while the resonance frequency in the transmissibility to the thigh increased as either arm or leg angles increased. If arm and leg position affect the transmission of vibration to the body, they will also affect the apparent mass of the body. However, there are no known studies of the effect of the position of a steering wheel or a wide range of positions of the feet on the apparent mass of the body.

The objective of this study was to determine the effects of steering wheel location and foot position on the vertical apparent mass measured at the seat surface. It was hypothesized that holding a steering wheel would restrain the motions of the upper body, increasing the damping 
and therefore decreasing the magnitude of the primary resonance in the apparent mass. Increasing the distance of the feet from the leading edge of a seat was expected to increase the mass supported on the seat surface and consequently increase the apparent mass at resonance.

\section{Methods and procedures}

\subsection{Apparatus}

The study was conducted using a 1-metre stroke vertical electro-hydraulic vibrator in the laboratory of the Human Factors Research Unit. A flat rigid seat with a rigid flat vertical backrest was attached to the vibrator platform. An adjustable footrest and an adjustable 'steering wheel' were also fixed to the platform (Fig. 1). The horizontal position and angle of inclination of the footrest, and the horizontal and vertical positions of the steering wheel, were adjustable. The force applied by the subjects to the footrest was measured by a set of digital scales (CPW-35 load cell scales; Adam Equipment, Danbury, USA) having a maximum rated load of $35 \mathrm{~kg}$ and \pm $0.02 \mathrm{~kg}$ linearity) attached to the footrest. The force applied to the steering wheel was measured indirectly using the same digital scales attached to the backrest.

\section{FIGURE 1 ABOUT HERE}

Measurements of the dynamic vertical force at the seat surface were made using a force plate (model $9281 \mathrm{~B}$, Kistler, Hook, UK). The signal from the force plate was amplified using a charge amplifier (Kistler 5007). Vibration on the platform was monitored using a piezo-resistive accelerometer (EGCSY-240D-10; Entran, Potterspury, UK) attached to the underside of the force platform.

\subsection{Postures}

The apparent mass on the seat surface was measured with subjects sitting in 21 different postures (Fig. 1, Table 1). These postures allowed the study of five horizontal positions of the steering wheel, three vertical position of the steering wheel, five horizontal distances of the 
footrest from the leading edge of the seat, five forces on the steering wheel, five forces on the footrest, and a 'no backrest' condition.

\section{TABLE 1 ABOUT HERE}

At the closest footrest position ( $\left.\mathrm{FH}_{\mathrm{H} 1}\right)$, the angle between the femur and fibular was 90 degrees. In the furthest position of the footrest $\left(\mathrm{F}_{\mathrm{H} 5}\right)$, the legs were outstretched and the femur and fibular were at $180^{\circ}$. The other three positions $\left(\mathrm{F}_{\mathrm{H} 2}, \mathrm{~F}_{\mathrm{H} 3}\right.$, and $\left.\mathrm{F}_{\mathrm{H} 4}\right)$ were equally spaced between the maximum and minimum positions appropriate for each subject. At each position, the angle of the footrest was adjusted so that the sole of the foot was at 90 degrees to the fibular. During these measurements the hands were in the lap and the backrest was reclined to 15 degrees. Subjects were supported by the backrest and asked to maintain a relaxed upright posture and place their feet on the footrest without exerting additional force.

The mid position for both the vertical and the horizontal adjustment of the steering wheel $\left(\mathrm{S}_{\mathrm{H} 3}\right.$, $\mathrm{S}_{\mathrm{v} 3}$ ) was set so that the forearm (radius) and upper arm (humerus) were at 45 degrees and the hands were vertically inline with the mid-point of the sternum. Subjects were supported by the footrest in position $\left(\mathrm{F}_{\mathrm{H} 4}\right)$ and by the reclined backrest. Subjects were asked not to exert additional unnecessary force to the steering wheel, backrest, or footrest.

At the closest steering wheel position $\left(\mathrm{S}_{\mathrm{H} 1}\right)$, the forearm (radius) and upper arm (humerus) were at 90 degrees. In the furthest position $\left(\mathrm{S}_{\mathrm{H} 5}\right)$ the arms were outstretched. The other three horizontal positions $\left(\mathrm{S}_{\mathrm{H} 2}, \mathrm{~S}_{\mathrm{H} 3}\right.$ and $\left.\mathrm{S}_{\mathrm{H} 4}\right)$ were set equidistance between the closest and furthest positions. The lowest position ( $\left.\mathrm{S}_{\mathrm{v} 1}\right)$ and the highest position $\left(\mathrm{S}_{\mathrm{v} 5}\right)$ of the steering wheel were set the same distance from the mid position $\left(\mathrm{S}_{\mathrm{V} 3}\right)$ as the extreme horizontal positions $\left(\mathrm{S}_{\mathrm{H} 1}\right.$ and $\left.\mathrm{S}_{\mathrm{H} 5}\right)$. Subjects were asked to maintain full contact with the backrest with all steering wheel positions.

When investigating the effect of force at the footrest, subjects were asked to exert $0,50,100$, 150 or $200 \mathrm{~N}$ while sitting with their hands in their laps and their legs almost outstretched (at position $\mathrm{F}_{\mathrm{H} 4}$ ) and the backrest reclined to $15^{\circ}$. Subjects monitored the force using a digital display connected to the scales. 
When investigating the effect of force at the hands, subjects were asked to apply $0,50,100$, 150 , or $200 \mathrm{~N}$ to the steering wheel in the mid-position $\left(\mathrm{S}_{\mathrm{H} 3}, \mathrm{~S}_{\mathrm{V}}\right)$. The subjects were supported by the backrest and the footrest in position $\mathrm{F}_{\mathrm{H} 4}$. The force applied to the steering wheel was measured using the digital scales attached to the backrest. The scales were zeroed with a subject supported by the backrest and holding the steering wheel before being was asked to exert force on the steering wheel.

In the 'no backrest' condition subjects were asked to sit in a relaxed upright posture without making contact with the reclined backrest. The footrest was adjusted to position $\mathrm{F}_{\mathrm{H} 4}$ and subjects placed their hands in their laps.

\subsection{Vibration}

The vibrator platform was excited using 60 -s periods of $1.0 \mathrm{~ms}^{-2}$ r.m.s. Gaussian random vibration (band-limited from 0.13 to $40 \mathrm{~Hz}$ using 8-pole Butterworth filters). The approximately flat constant bandwidth acceleration spectra were generated and analysed using an HVLab data acquisition and analysis system (version 3.81; University of Southampton, UK). Different random input signals were generated for each subject. The measured force and acceleration were acquired at 500 samples per second via $167 \mathrm{~Hz}$ anti-aliasing filters.

\subsection{Subjects}

Twelve healthy male subjects aged 22 to 48 years (mean 30.7 years) participated in the experiment. The subjects ranged in stature from 1.69 to $1.89 \mathrm{~m}$ (mean $1.80 \mathrm{~m}$ ) and ranged in weight between 64.5 and $100.7 \mathrm{~kg}$ (mean $77.1 \mathrm{~kg}$ ). All subjects were exposed to all conditions in a single session lasting approximately 90 minutes. Subjects wore a loose fitting lap belt and had access to an emergency stop button. Subjects gave informed consent to participate in the experiment that was approved by the Human Experimentation, Safety and Ethics Committee of the Institute of Sound and Vibration Research at the University of Southampton.

\subsection{Analysis}


Transfer functions were calculated between the vertical seat acceleration and the vertical force at the seat surface, to give the apparent masses of the subjects. Apparent mass was calculated using the cross-spectral density (CSD) technique with a resolution of $0.195 \mathrm{~Hz}$. The apparent mass, $H_{i o}(f)$, was calculated from the ratio of the CSD of acceleration at the seat, $G_{i o}(f)$, to the power spectral density (PSD) of the acceleration at the seat, $G_{i i}(f)$ :

$$
H_{i o}(f)=\frac{G_{i o}(f)}{G_{i i}(f)} .
$$

Prior to the calculation of the apparent mass, mass cancellation of the mass of the force platform top-plate $(33.0 \mathrm{~kg})$ was performed in the time domain to remove its influence from the measured force: the acceleration time-history on the seat surface was multiplied by the mass of the force platform, which was then subtracted from the measured force.

The medians of the primary resonance frequencies and the apparent masses at resonance for the 12 subjects were calculated for each condition. The apparent mass at the primary resonance frequency was assumed to be the greatest apparent mass over the measurement range. The primary resonance frequency was defined as the frequency at which the apparent mass was greatest.

Statistical analysis was performed using SPSS (version 14). Non-parametric tests (the Friedman test for $k$-related samples and the Wilcoxon matched-pairs signed ranks test for tworelated samples) were employed. Non-parametric statistics were used to avoid assuming a normal distribution in the data.

\section{Results}

\subsection{Effect of backrest and steering wheel contact}

The effects of contact with the backrest and holding the steering wheel on the median modulus and phase of the apparent masses of the 12 subjects are shown in Fig. 2. The median resonance frequency increased from $4.8 \mathrm{~Hz}$ with 'no backrest contact' to $6.7 \mathrm{~Hz}$ when the back 
was supported by the backrest reclined to $15^{\circ}$ (Table $2 ; p<0.01$, Wilcoxon matched-pairs signed ranks). At the lowest frequencies, the mass supported on the seat surface was reduced by $8.5 \mathrm{~kg}$ when supported by the backrest. The apparent mass at resonance was also significantly reduced with the backrest $(p<0.01)$.

\section{FIGURE 2 AND TABLE 2 ABOUT HERE}

The median resonance frequency was similar, irrespective of whether subjects supported by the backrest had their hands in their laps or held the steering wheel $(6.7 \mathrm{~Hz}$ compared to $6.8 \mathrm{~Hz} ; p$ $=0.27)$. Although holding the steering wheel did not affect the resonance frequency, it tended to decrease the apparent mass at resonance and the apparent mass at $0.4 \mathrm{~Hz}(p<0.01)$. The decrease in the response at $0.4 \mathrm{~Hz}$ is consistent with the steering wheel supporting some of the mass of the arms. When subjects held the steering wheel, the response between 8 and $14 \mathrm{~Hz}$ tended to increase $(p<0.01$ at $12.0 \mathrm{~Hz})$ and, in some subjects, there was evidence of a further resonance occurring at around $4 \mathrm{~Hz}$.

\subsection{Effect of steering wheel position}

Changing the horizontal position of the steering wheel had no effect on the proportion of the subject weight supported on the seat surface $(p>0.63$ at $0.4 \mathrm{~Hz}$, Friedman). The apparent mass at frequencies greater than $10 \mathrm{~Hz}$ was also little affected by the horizontal position of the steering wheel. However, as the steering wheel moved from the closest position $\left(\mathrm{S}_{\mathrm{H} 1}\right)$ to the furthest position $\left(\mathrm{S}_{\mathrm{H} 5}\right)$, the median apparent mass decreased at the primary resonance from $84.6 \mathrm{~kg}$ to $75.0 \mathrm{~kg}$ (Table 2, Fig. 3) and increased at the secondary resonance around $4 \mathrm{~Hz}$.

\section{FIGURE 3 ABOUT HERE}

The vertical position of the steering wheel had little effect of the apparent mass at any frequency (Fig. 4, Table 2): there were no significant changes in the response at $0.4 \mathrm{~Hz}(p=0.56)$, at resonance $(p=0.56)$, or at $12.0 \mathrm{~Hz}(p=0.56)$. However, the resonance frequency increased slightly as the steering wheel was raised $(p=0.02)$. 


\section{FIGURE 4 ABOUT HERE}

\subsection{Effect of horizontal footrest position}

Increasing the distance of the footrest from the leading edge of the seat tended to increase the apparent mass at resonance (Fig. 5, Table 2; $p<0.01$, Friedman) and at low frequencies (at 0.4 $\mathrm{Hz}, \mathrm{p}<0.01$, Friedman). There was a tendency for the principal peak in the apparent mass to narrow as the feet were positioned further forward, but the frequency of the primary resonance was not significantly changed $(p=0.16$, Friedman).

\section{FIGURE 5 ABOUT HERE}

\subsection{Effect of force applied to the footrest and the steering wheel}

Increasing the force applied to the steering wheel reduced the apparent mass at the principal resonance (Fig. 6 and Table 2; Friedman $p<0.01$ ). To a lesser extent, the apparent mass at 0.4 $\mathrm{Hz}$ also decreased as the force on the steering wheel increased (Friedman $p<0.01$ ). The median resonance frequency increased from $6.8 \mathrm{~Hz}$ to $7.6 \mathrm{~Hz}$ as the force increased from $0 \mathrm{~N}$ to $150 \mathrm{~N}(p=0.07)$ but decreased to $6.8 \mathrm{~Hz}$ as the force was increased further to $200 \mathrm{~N}(p=$ $0.05)$.

\section{FIGURE 6 ABOUT HERE}

Increasing the force applied to the footrest reduced the apparent mass at the principal resonance (Fig. 7 and Table 2; Friedman, $p=0.02$ ), similar to the effect of force on the steering wheel, but less marked. As the force on the footrest increased, the apparent mass reduced at $0.4 \mathrm{~Hz}$ (Friedman, $p<0.02$ ) and at $12.0 \mathrm{~Hz}$ (Friedman, $p=0.01$ ). The resonance frequency was unaffected by footrest force (Friedman, $p=0.43$ ).

\section{FIGURE 7 ABOUT HERE}

\section{Discussion}

\subsection{Effect of backrest and steering wheel contact}


The increase in the apparent mass resonance frequency caused by contact with the rigid backrest is consistent with previous studies $[8,11,13]$. This has previously been explained by the backrest providing an additional constraint to the motions of the body. Contact with a reclined backrest has increased the resonance frequency compared to contact with an upright backrest [e.g., 11], possibly due to a greater proportion of the body mass being supported on the backrest and increased backrest contact further constraining the motions of the body.

In the present study, both the mass supported on the seat surface and the apparent mass at resonance decreased when the back was supported by a reclined backrest compared to the "no backrest' condition. Rakheja et al. [8] concluded that both the mass supported on the seat surface and the apparent mass at resonance were increased by a back support, but the 'no backrest' data they used were drawn from previous measurements (ISO 5982 [15]) and may not have been directly comparable data (e.g., from subjects of similar weight).

The mass supported on the seat at low frequencies reduced slightly when the hands were placed on the steering wheel, consistent with the steering wheel supporting some of the subject mass. There was also a lower apparent mass around the primary resonance when subjects held the steering wheel; however the ratio between the peak apparent mass and the apparent mass at $0.4 \mathrm{~Hz}$ (called 'peak ratio') was unaffected by hand position ( $\approx 1.6$ in both cases). Rakheja et al. [8] found that this ratio was lower when subjects held a steering wheel $(\approx 1.4)$ compared to a hands in lap posture $(\approx 1.7)$. The reason for this difference between the studies is not clear but the postures may have differed: their subjects adopted an uncontrolled 'comfortable' foot position whereas subjects in the present study had a fixed angle of $157.5^{\circ}$ $\left(\mathrm{F}_{\mathrm{H}}\right)$ between the femur and fibular. When Rakheja et al. [8] asked their subjects to position their feet $7.5 \mathrm{~cm}$ further from their bodies, the effect of steering wheel contact on the 'peak ratio' was less marked. However, foot position had little effect on the apparent mass when the hands were in the lap, implying an interaction between the effect of foot position and steering wheel contact. In the present study, the steering wheel was adjusted for each subject so that the arm angle was $45^{\circ}$, whereas Rakheja et al. used a fixed steering wheel position. In the present study, the apparent mass at resonance decreased as the steering wheel was moved away from 
the body. The reduced apparent mass at resonance found by Rakheja et al. [8] when subjects held a steering wheel is consistent with the steering wheel being further from the body and the arms straighter. In the present study, and in a study by Wang et al. [9], the resonance frequency was largely unaffected by steering wheel contact, whereas Rakheja et al. [8] found that the resonance frequency decreased with steering wheel contact, possibly due to the postural differences described above.

\subsection{Effect of the steering wheel position}

As the steering wheel moved away from the body, the proportion of body weight supported on the seat surface (e.g., the apparent mass at $0.4 \mathrm{~Hz}$ ) was unchanged but the apparent mass around $4 \mathrm{~Hz}$ increased and the apparent mass around the principal resonance decreased. Consequently, at the furthest steering wheel position there were two distinct peaks in the median apparent mass: at $4.4 \mathrm{~Hz}$ and $6.6 \mathrm{~Hz}$. The apparent mass varied between subjects, as shown for the five horizontal positions of the steering wheel in Figure 8; the inter-subject variability was similar in the other postures. All subjects exhibited evidence of a peak in their apparent mass at a frequency less than their primary resonance, with both peaks affected by the horizontal position of the steering wheel (Fig. 8). The systematic change in apparent mass around $4 \mathrm{~Hz}$ may have been caused by a resonance of the arms and shoulders at this frequency.

\section{FIGURE 8 ABOUT HERE}

The reduction in the apparent mass at the primary resonance when subjects made contact with the steering wheel suggests the response of the arms interacted with the body movements associated with the primary resonance. As the arms were straightened, the apparent mass at 4.0 Hz increased while the apparent mass around the primary resonance decreased. This might be explained by increased influenced of the arm-shoulder response as the arms were extended. Nishiyama et al. [14] measured the vibration transmitted to the arms from the seat surface of subjects sitting in a car driving posture holding a steering wheel. They found that the transmissibility was dependent on the arm angle, with more vibration being transmitted to the 
arms as they were straightened. The transmissibility between the seat surface and the mid-point of the biceps increased from 3.7 to 4.5 as the arms straightened from $90^{\circ}$ to $180^{\circ}$, while the transmissibility to the centre of the chest reduced from 1.7 to 1.6. Previous studies have found the principal resonance is associated with the motions of the upper-body [16, 17], so the decrease in transmission of vibration to the chest as the arms are extended is consistent with the decrease in the apparent mass at resonance in the present study. The transmission of vertical seat vibration to an unsupported hand held in front of the body has peaks at approximately $2 \mathrm{~Hz}$ and $5 \mathrm{~Hz}$, with the magnitude of the $2-\mathrm{Hz}$ peak higher and the magnitude of the $5-\mathrm{Hz}$ peak lower when the hand is further from the body [18]. These lower resonance frequencies than in the present study (i.e., 2 and $5 \mathrm{~Hz}$ compared with approximately 4 and $7 \mathrm{~Hz}$ ) may be attributed to the use of an upright posture and the absence of a backrest.

Changes in the position of the arms can lead to other postural changes in the body thereby altering muscle tension and mass distribution. Changes in muscle tension can affect the primary resonance frequency (e.g. [2]) while changes in mass distribution can affect the mass supported on the seat surface (e.g. [12]). Neither the frequency of the primary resonance nor the mass supported on the seat surface were significantly affected by arm position, so while an influence of muscle tension and mass distribution cannot be entirely discounted there is no clear evidence of them affecting the results.

Although the horizontal and vertical adjustments of the steering wheel were of the same size, vertical adjustment had less influence on the apparent mass. This may have arisen because the full range of vertical positions of the steering wheel resulted in less change to the angle between forearm and upper-arm than the full range of horizontal positions of the steering wheel.

In this study the handles of the 'steering wheel' were aligned vertically $\left(0^{\circ}\right.$, Figure 1$)$ whereas in a car the steering wheel is usually aligned at an angle between 0 and $25^{\circ}$. Changing the angle of the steering wheel may affect the angle between the fore-arm and hand but have less effect on the angle between the forearm and the upper-arm. Changes in the vertical position of the steering wheel altered the angle between the fore-arm and hand but had only a minor influence 
on the apparent mass, so it is expected that the angle of the steering wheel will also have had only a small influence on the apparent mass measured at the seat.

\subsection{Effect of footrest position}

When the feet are lowered relative to a seat surface, the mass supported on the seat surface and the apparent mass at resonance both increase [12]. In the present study, similar changes were found when the feet moved forward: the mass supported on the seat surface decreased, indicating that the backrest and footrest supported a greater proportion of the subject weight. If the primary resonance of the body is represented as a single degree-of-freedom mass-springdamper system, a reduction in moving mass with no change in stiffness would increase the resonance frequency. Nawayseh and Griffin [12] found the resonance frequency was independent of foot height and so they hypothesised that either the primary resonance frequency depends on the motions of the upper-body regardless of the motion of the legs or that there was a corresponding decrease in the stiffness of the thighs as the mass supported on the seat surface reduced. In the present study, the resonance frequency tended to increase as the legs were straightened from position $\mathrm{F}_{\mathrm{H} 1}$ (minimum) to position $\mathrm{F}_{\mathrm{H} 3}$ (mid) and then decrease as the legs straightened from position $\mathrm{F}_{\mathrm{H} 3}$ to $\mathrm{F}_{\mathrm{H} 5}$ (maximum): significantly different between $\mathrm{F}_{\mathrm{H} 1}$ and $\mathrm{F}_{\mathrm{H} 3}$, and between $\mathrm{F}_{\mathrm{H} 3}$ and $\mathrm{F}_{\mathrm{H} 5}$. The results are consistent with two counteracting influences of foot position on the resonance frequency: as the feet move forward the reduced mass on the seat surface tends to increase the resonance frequency while the reduced thigh contact tends to reduce their stiffness and the resonance frequency.

\subsection{Effect of footrest and steering wheel force}

As a backrest is reclined, more mass is supported on the backrest, the apparent mass at resonance decreases, and the resonance frequency of the apparent mass increases [11]. In the current study, as the force on the backrest increased due to greater forces applied to either the footrest or the steering wheel, the apparent mass at resonance decreased but the resonance frequency was unchanged. This suggests the increase in the resonance frequency when reclining a backrest may be associated with the angle of the upper-body as opposed to the 
force applied to the backrest. The absence of a change in the resonance frequency with increased force applied to the steering wheel or the footrest suggests these forces did not tense the body in the same way as in previous studies where the resonance frequency was greater in 'tensed' than 'un-tensed' postures e.g., $[2,3,5,6]$.

\section{Conclusions}

The median principal resonance frequency in the apparent mass of the body sitting in the posture of a car passenger (hands in lap, backrest at $15^{\circ}$ ) was $6.7 \mathrm{~Hz}$ compared to $4.8 \mathrm{~Hz}$ when sitting upright with no backrest. Both the mass supported on the seat surface, and the apparent mass at resonance, were less in the car passenger posture than when sitting upright with no backrest.

When subjects supported by a backrest held a steering wheel, an additional resonance was evident around $4 \mathrm{~Hz}$. Moving the steering wheel away from the body did not change the proportion of the subject mass supported on the seat surface, but the apparent mass at the primary resonance reduced, and the apparent mass at the $4 \mathrm{~Hz}$ resonance increased, suggesting the $4 \mathrm{~Hz}$ resonance is associated with the arms and shoulders. Raising the steering wheel had a similar, but smaller, effect to moving the steering wheel forward.

As the feet moved forward, the mass supported on the horizontal seat surface decreased, indicating that the backrest and footrest supported a greater proportion of the subject weight.

Applying force to either the steering wheel or the footrest did not affect the resonance frequency but reduced the apparent mass at resonance and decreased the mass supported on the seat surface.

The results show that the apparent mass of the human body sitting in the posture of a car driver or car passenger differs from that when sitting upright with no backrest contact. Systematic variations in the apparent mass have been found when changing the positions of the feet and the hands. As the transmission of vibration through a seat is influenced by the apparent mass of the seat occupant, contact with the backrest and hand and foot position can be expected to 
Published as: Apparent mass of the human body in the vertical direction: Effect of footrest and a steering wheel Toward, M. G. R. \& Griffin, M. J. 26 Apr 2010 In : Journal of Sound and Vibration. 329, 9, p. 1586-1596.

affect seat transmissibility and should be taken into account when constructing physical or mathematical models of the dynamic response of the body. 


\section{References}

[1] C. Corbridge, M.J. Griffin, P. Harborough, Seat dynamics and passenger comfort. Institute of Mechanical Engineers, Part F: Journal of Rail and Rapid Transit 203 (1989) 57-64.

[2] T.E. Fairley, M.J. Griffin, The apparent mass of the seated human body: vertical vibration. Journal of Biomechanics 22 (1989) 81-94.

[3] T. Miwa, Mechanical impedance of the human body in various postures. Industrial Health 13 (1973) 1-22.

[4] S. Kitazaki, M.J. Griffin, 998, Resonance behaviour of the seated human body and effects of posture. Journal of Biomechanics 31 (1998) 143-149.

[5] N.J. Mansfield, M.J. Griffin, Effects of posture and vibration magnitude on apparent mass and pelvis rotation during exposure to whole-body vertical vibration. Journal of Sound and Vibration 253 (1) (2002) 93-107.

[6] Y. Matsumoto, M.J. Griffin, Effect of muscle tension on non-linearities in the apparent masses of seated subjects exposed to vertical whole-body vibration. Journal of Sound and Vibration 253 (2002) 77-92.

[7] N. Nawayseh, M.J. Griffin. Tri-axial forces at the seat and backrest during whole-body vertical vibration. Journal of Sound and Vibration 277 (2004) 309-326.

[8] S. Rakheja, I. Stiharu, P.É. Boileau, Seated occupant apparent mass characteristics under automotive posture and vertical vibration. Journal of Sound and Vibration 253 (1) (2002) 57-75.

[9] W. Wang, S. Rakheja, P.É. Boileau, Effects of sitting postures on biodynamic response of seated occupant under vertical vibration. International Journal of Industrial Ergonomics 34 (2004) 289-306.

[10] N. Nawayseh, M.J. Griffin, Effect of seat surface angle on forces at the seat surface during whole-body vertical vibration. Journal of Sound and Vibration 284 (2005) 613-634. 
[11] M.G.R Toward, M.J. Griffin, Apparent mass of the human body in the vertical direction:

Effect of seat backrest. Journal of Sound and Vibration (2009) doi:10.1016/j.jsv.2009.07.012.

[12] N. Nawayseh, M.J. Griffin, Non-linear dual-axis biodynamic response to vertical whole-body vibration. Journal of Sound and Vibration 268 (2003) 503-523.

[13] S. Rakheja, I. Stiharu, P.É. Boileau, Seated occupant interactions with seat backrest and pan, and biodynamic response under vertical vibration. Journal of Sound and Vibration 298 (1) (2006) 651-671.

[14] S. Nishiyama, N. Uesugi, T. Takeshima, Y. Kano, H. Togii, Research on vibration characteristics between human body and seat, steering wheel, and pedals (effects of seat position on ride comfort). Journal of Sound and Vibration 236 (2000) 1-21.

[15] International Organization for Standardisation ISO 5982, Mechanical vibration and shockRange of idealized values to characterize seated-body biodynamic response under vertical vibration, International Standard, 2001.

[16] F.W. Hagena, C.J. Wirth, J. Piehler, W. Plitz, G.O.Hofmann, Th. Swingers, In vivo experiments on the response of the human spine to sinusoidal Gz-vibration, $A G A R D$ Conference Proceedings 378 (1985) 1-12.

[17] Y. Matsumoto, M.J. Griffin, Movement of the upper-body of seated subjects exposed to vertical whole-body vibration at the principle resonance frequency. Journal of Sound and Vibration 215 (1998) 743-762.

[18] M.J. Griffin, Handbook of Human Vibration, Academic Press, London (1990). 
Table 1 Position of the hands and feet, force applied to the steering wheel and backrest, and backrest support in each of the 21 postures. The groups of comparable conditions are highlighted.

\begin{tabular}{|c|c|c|c|c|c|c|}
\hline Posture & $\begin{array}{l}\text { Horizontal } \\
\text { hand position }\end{array}$ & $\begin{array}{l}\text { Vertical hand } \\
\text { position }\end{array}$ & Foot position & $\begin{array}{l}\text { Force applied } \\
\text { to steering } \\
\text { wheel }\end{array}$ & $\begin{array}{l}\text { Force applied } \\
\text { to footrest }\end{array}$ & Backrest \\
\hline 1 & Lap & Lap & $\mathrm{F}_{\mathrm{H} 4}$ & 0 & 0 & No backrest \\
\hline 2 & Lap & Lap & $\mathrm{F}_{\mathrm{H} 4}$ & 0 & 0 & $15^{\circ}$ \\
\hline $2^{*}$ & Lap & Lap & $\mathrm{F}_{\mathrm{H} 4}$ & 0 & 0 & $15^{\circ}$ \\
\hline 3 & $\mathrm{~S}_{\mathrm{H} 3}$ & $\mathrm{~S}_{\mathrm{V} 3}$ & $\mathrm{~F}_{\mathrm{H} 4}$ & 0 & 0 & $15^{\circ}$ \\
\hline 4 & $\mathrm{~S}_{\mathrm{H} 1}(\mathrm{~min})$ & $\mathrm{Sv}_{3}$ & $\mathrm{~F}_{\mathrm{H} 4}$ & 0 & 0 & $15^{\circ}$ \\
\hline 5 & $\mathrm{~S}_{\mathrm{H} 2}$ & $\mathrm{~S}_{3}$ & $\mathrm{~F}_{\mathrm{H} 4}$ & 0 & 0 & $15^{\circ}$ \\
\hline $3^{*}$ & $\mathrm{~S}_{\mathrm{H} 3}$ & $\mathrm{~S}_{2}$ & $\mathrm{~F}_{\mathrm{H} 4}$ & 0 & 0 & $15^{\circ}$ \\
\hline 6 & $\mathrm{~S}_{\mathrm{H} 4}$ & $\mathrm{~S}_{\mathrm{V} 3}$ & $\mathrm{~F}_{\mathrm{H} 4}$ & 0 & 0 & $15^{\circ}$ \\
\hline 7 & $\mathrm{~S}_{\mathrm{H} 5}(\max )$ & $\mathrm{S}_{\mathrm{V}}$ & $\mathrm{F}_{\mathrm{H} 4}$ & 0 & 0 & $15^{\circ}$ \\
\hline 8 & $\mathrm{~S}_{\mathrm{H} 3}$ & $\mathrm{~S}_{\mathrm{V} 1}(\min )$ & $\mathrm{F}_{\mathrm{H} 4}$ & 0 & 0 & $15^{\circ}$ \\
\hline $3^{*}$ & $\mathrm{~S}_{\mathrm{H} 3}$ & $\mathrm{~S}_{\mathrm{V}} 3$ (mid) & $\mathrm{F}_{\mathrm{H} 4}$ & 0 & 0 & $15^{\circ}$ \\
\hline 9 & $\mathrm{~S}_{\mathrm{H} 3}$ & Sv5 (max) & $\mathrm{F}_{\mathrm{H} 4}$ & 0 & 0 & $15^{\circ}$ \\
\hline 10 & Lap & Lap & $\mathrm{F}_{\mathrm{H} 1}(\min )$ & 0 & 0 & $15^{\circ}$ \\
\hline 11 & Lap & Lap & $\mathrm{F}_{\mathrm{H} 2}$ & 0 & 0 & $15^{\circ}$ \\
\hline 12 & Lap & Lap & $\mathrm{F}_{\mathrm{H} 3}(\mathrm{mid})$ & 0 & 0 & $15^{\circ}$ \\
\hline $2^{*}$ & Lap & Lap & $\mathrm{F}_{\mathrm{H} 4}$ & 0 & 0 & $15^{\circ}$ \\
\hline 13 & Lap & Lap & $\mathrm{F}_{\text {H5 }}$ (max) & 0 & 0 & $15^{\circ}$ \\
\hline $3^{*}$ & $\mathrm{~S}_{\mathrm{H} 3}$ & $\mathrm{~S}_{\mathrm{V} 3}$ & $\mathrm{~F}_{\mathrm{H} 4}$ & $0 \mathrm{~N}$ & 0 & $15^{\circ}$ \\
\hline 14 & $\mathrm{~S}_{\mathrm{H} 3}$ & $\mathrm{~S}_{\mathrm{V} 3}$ & $\mathrm{~F}_{\mathrm{H} 4}$ & $50 \mathrm{~N}$ & 0 & $15^{\circ}$ \\
\hline 15 & $\mathrm{~S}_{\mathrm{H} 3}$ & $\mathrm{~S}_{\mathrm{V} 3}$ & $\mathrm{~F}_{\mathrm{H} 4}$ & $100 \mathrm{~N}$ & 0 & $15^{\circ}$ \\
\hline 16 & $\mathrm{~S}_{\mathrm{H} 3}$ & $\mathrm{~S}_{\mathrm{V} 3}$ & $\mathrm{~F}_{\mathrm{H} 4}$ & $150 \mathrm{~N}$ & 0 & $15^{\circ}$ \\
\hline 17 & $\mathrm{~S}_{\mathrm{H} 3}$ & $\mathrm{~S}_{\mathrm{V} 3}$ & $\mathrm{~F}_{\mathrm{H} 4}$ & $200 \mathrm{~N}$ & 0 & $15^{\circ}$ \\
\hline $2^{*}$ & Lap & Lap & $\mathrm{F}_{\mathrm{H} 4}$ & 0 & $0 \mathrm{~N}$ & $15^{\circ}$ \\
\hline 18 & Lap & Lap & $\mathrm{F}_{\mathrm{H} 4}$ & 0 & $50 \mathrm{~N}$ & $15^{\circ}$ \\
\hline 19 & Lap & Lap & $\mathrm{F}_{\mathrm{H} 4}$ & 0 & $100 \mathrm{~N}$ & $15^{\circ}$ \\
\hline 20 & Lap & Lap & $\mathrm{F}_{\mathrm{H} 4}$ & 0 & $150 \mathrm{~N}$ & $15^{\circ}$ \\
\hline 21 & Lap & Lap & $\mathrm{F}_{\mathrm{H} 4}$ & 0 & $200 \mathrm{~N}$ & $15^{\circ}$ \\
\hline
\end{tabular}

*The same as previous posture with this number. 
Table 2 Effect of posture on the primary resonance frequencies and apparent masses at resonance, at $0.4 \mathrm{~Hz}$ and at $12.0 \mathrm{~Hz}$ (medians of 12 subjects); as well as interquartile values (25\%, 75\%).

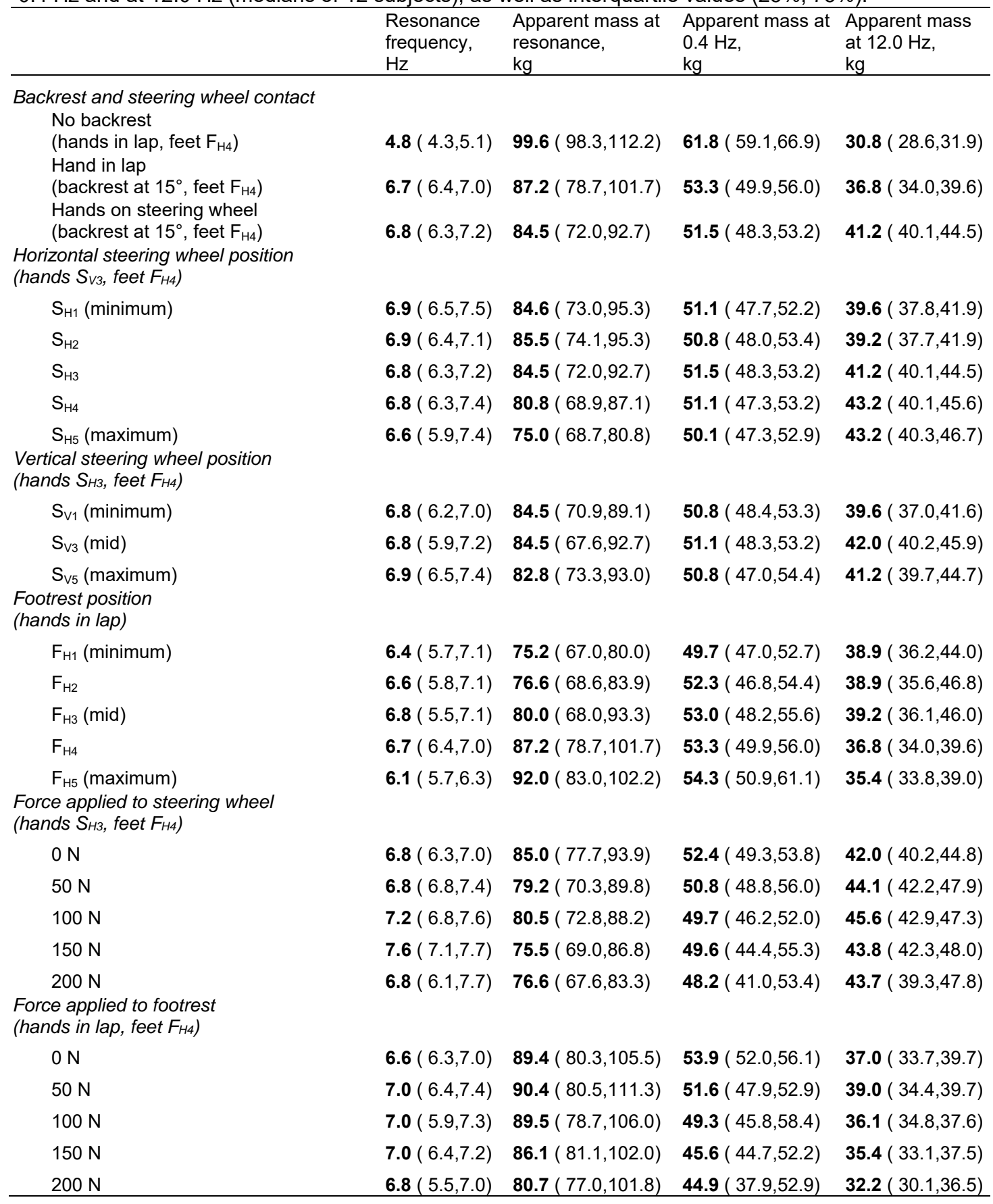




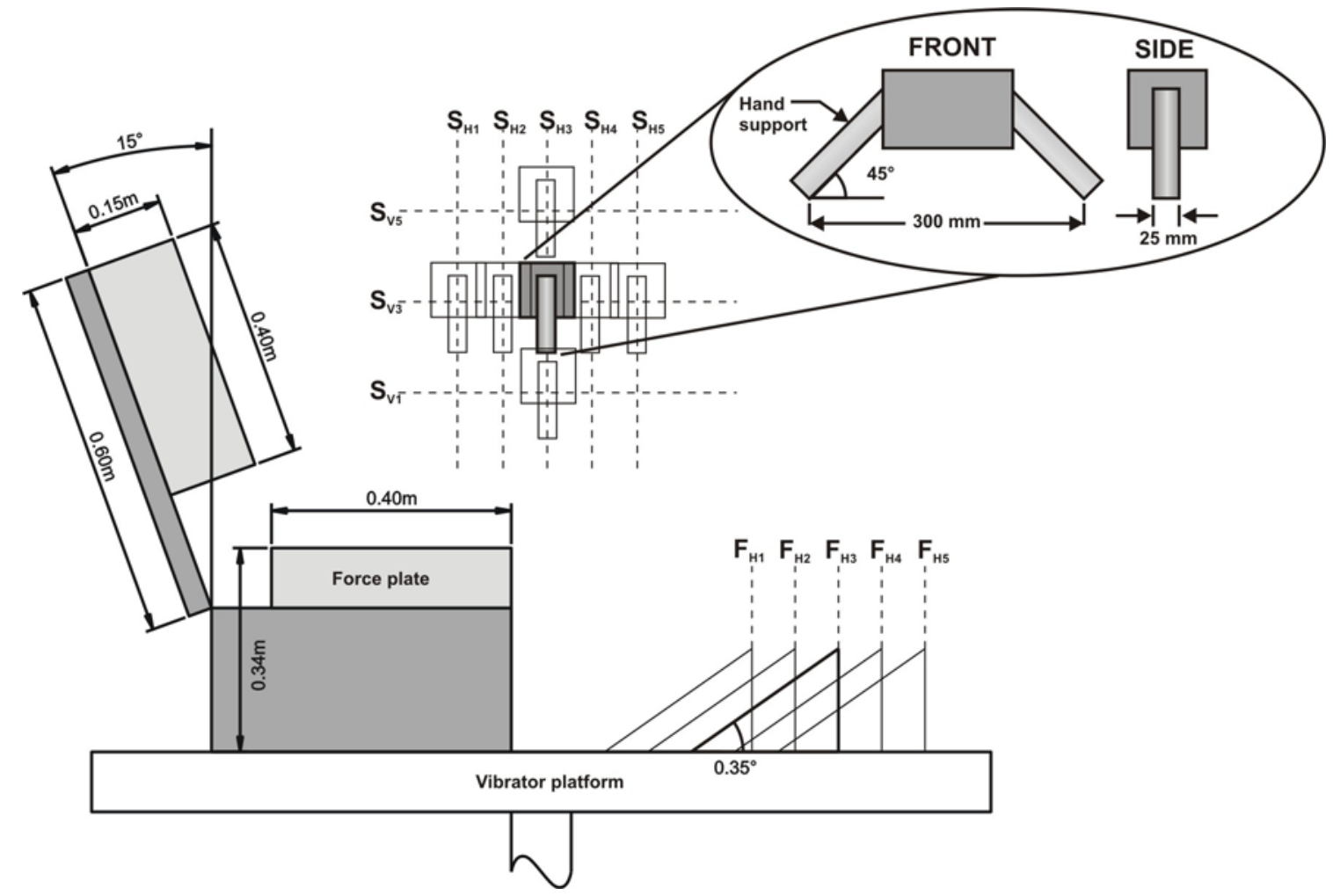

Fig. 1 Experimental apparatus. 


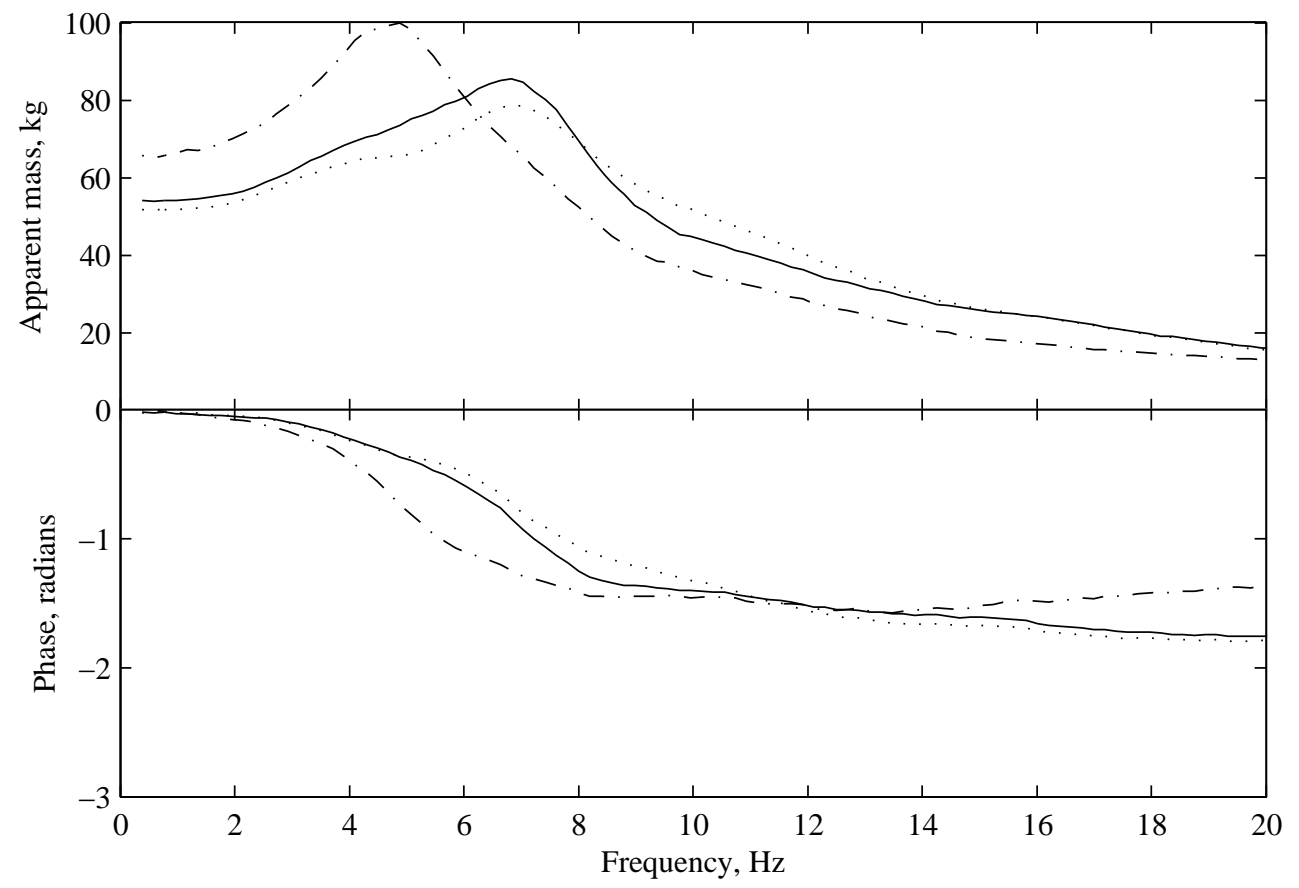

Fig. 2 Effect of backrest and steering wheel contact on apparent mass (medians of 12 subjects with the footrest at position $\mathrm{F}_{\mathrm{H} 4}$ ): $-\cdot-\cdot-$, No backrest contact (hands in lap); _- Backrest at $15^{\circ}$ (hands in lap); $\cdots$, , Hands on steering wheel (backrest at $\left.15^{\circ}\right)$. 
Published as: Apparent mass of the human body in the vertical direction: Effect of footrest and a steering wheel Toward, M. G. R. \& Griffin, M. J. 26 Apr 2010 In : Journal of Sound and Vibration. 329, 9, p. 1586-1596.

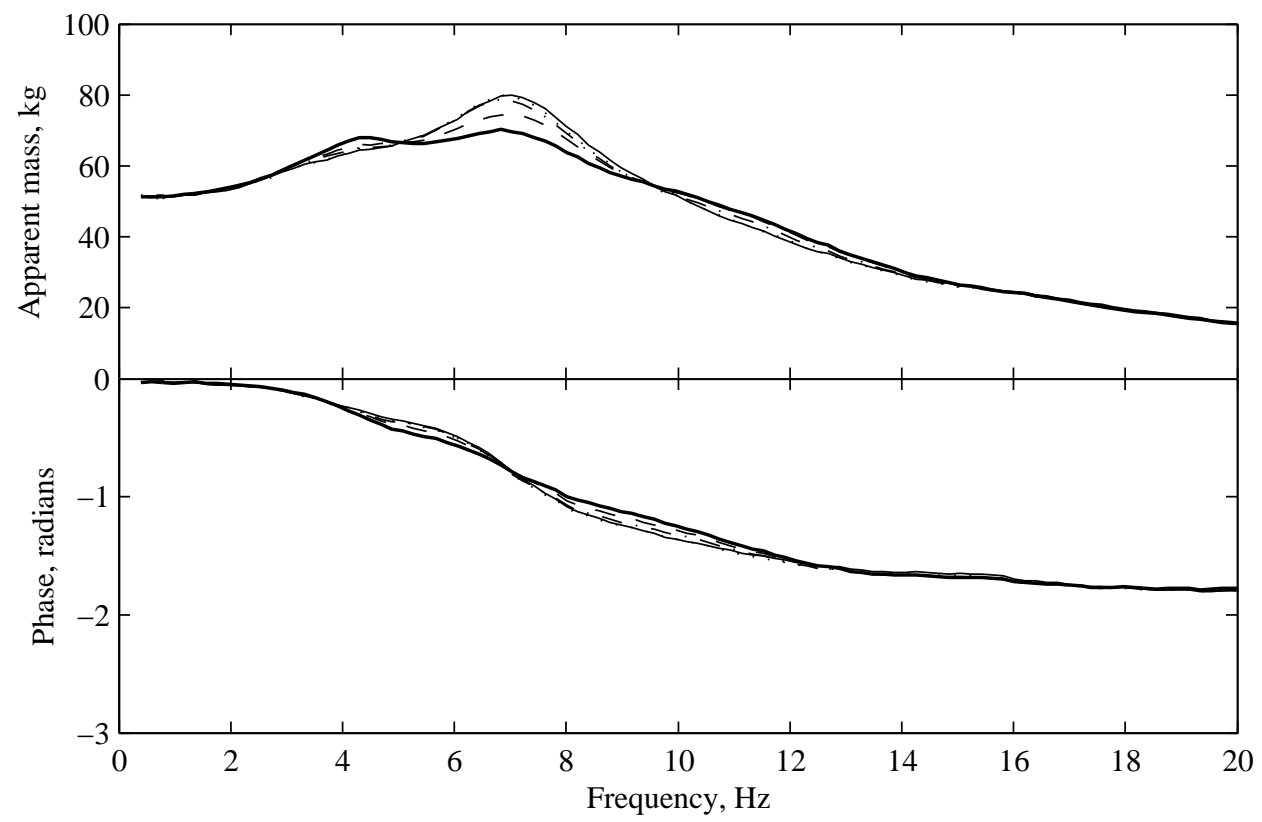

Fig. 3 Effect of horizontal position of the steering wheel on apparent mass (medians of 12 subjects with steering wheel at vertical position $\mathrm{S}_{\mathrm{V} 3}$ and footrest at $\left.\mathrm{F}_{\mathrm{H} 4}\right)$ : $\mathrm{S}_{\mathrm{H} 1}(-), \mathrm{S}_{\mathrm{H} 2}(), \mathrm{S}_{\mathrm{H} 3}(-), \mathrm{S}_{\mathrm{H} 4}(---)$ and $\mathrm{S}_{\mathrm{H} 5}$ (一). 
Published as: Apparent mass of the human body in the vertical direction: Effect of footrest and a steering wheel Toward, M. G. R. \& Griffin, M. J. 26 Apr 2010 In : Journal of Sound and Vibration. 329, 9, p. 1586-1596.

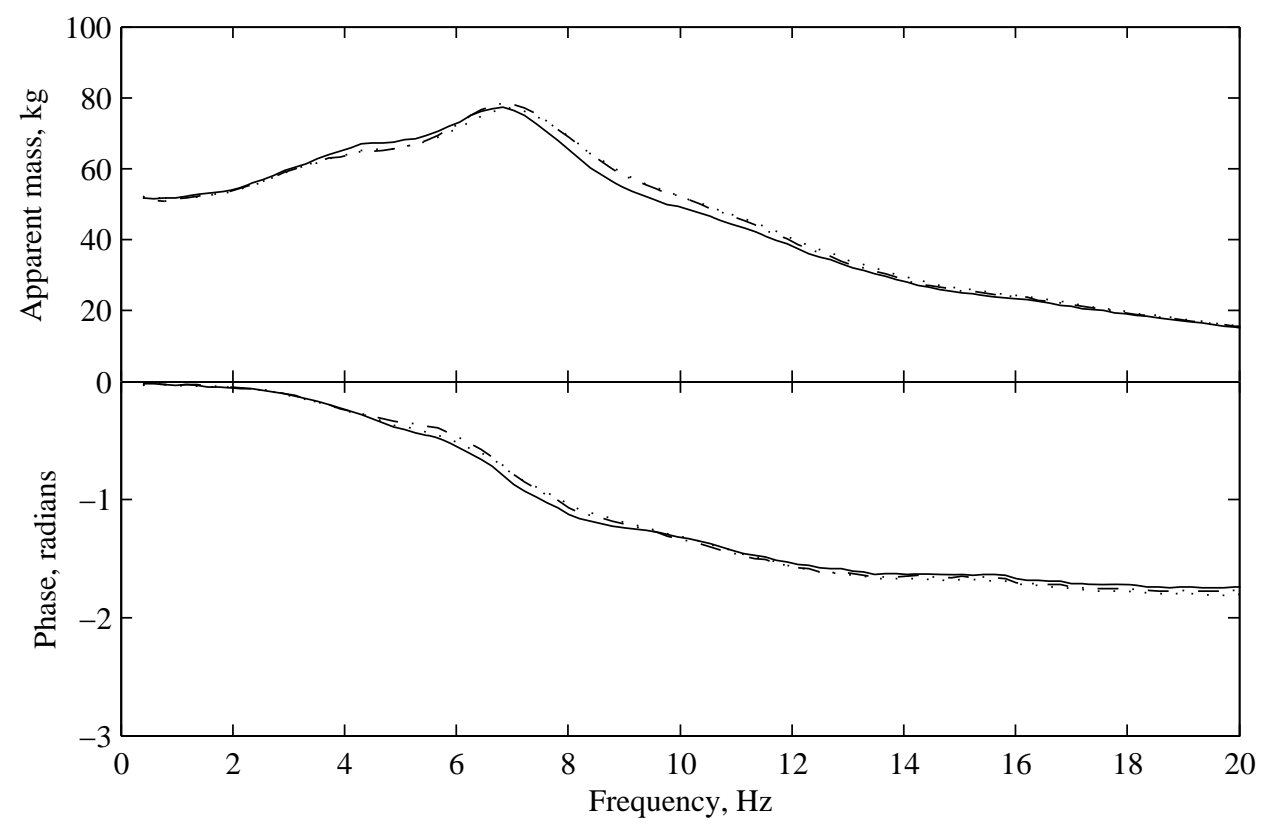

Fig. 4 Effect of vertical position of the steering wheel on apparent mass (medians of 12 subjects with the steering wheel at horizontal position $\mathrm{S}_{\mathrm{H} 3}$ and footrest at $\left.\mathrm{F}_{\mathrm{H} 4}\right)$ : $\mathrm{S}_{\mathrm{V} 1}(-), \mathrm{S}_{\mathrm{V}}()$ and $\mathrm{S}_{\mathrm{H} 5}(-)$ at $1.0 \mathrm{~ms}-2$ r.m.s. 


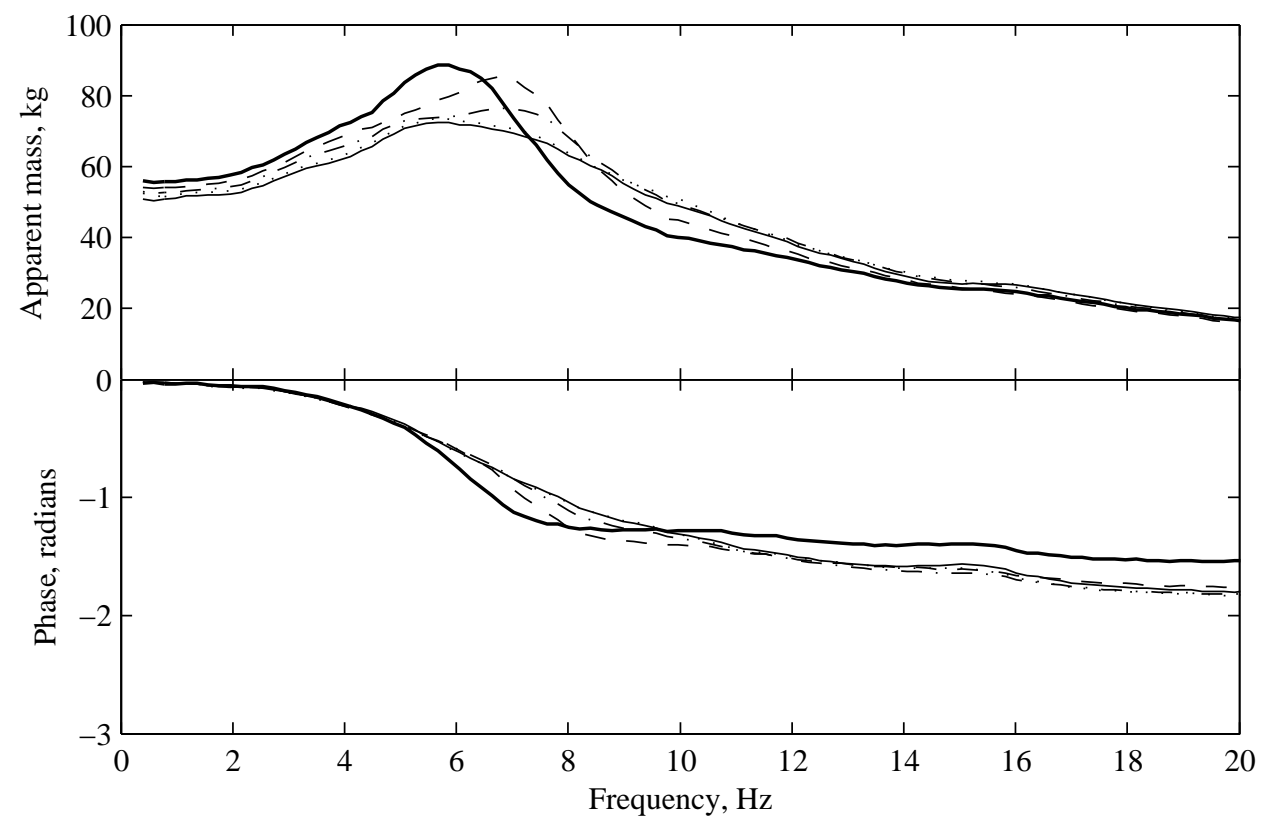

Fig. 5 Effect of horizontal position of the footrest on apparent mass (medians of 12 subjects with hands in lap): $\mathrm{F}_{\mathrm{H} 1}(-), \mathrm{F}_{\mathrm{H} 2}(), \mathrm{F}_{\mathrm{H} 3}(-), \mathrm{F}_{\mathrm{H} 4}(---)$ and $\mathrm{F}_{\mathrm{H} 5}(-)$. 
Published as: Apparent mass of the human body in the vertical direction: Effect of footrest and a steering wheel Toward, M. G. R. \& Griffin, M. J. 26 Apr 2010 In : Journal of Sound and Vibration. 329, 9, p. 1586-1596.

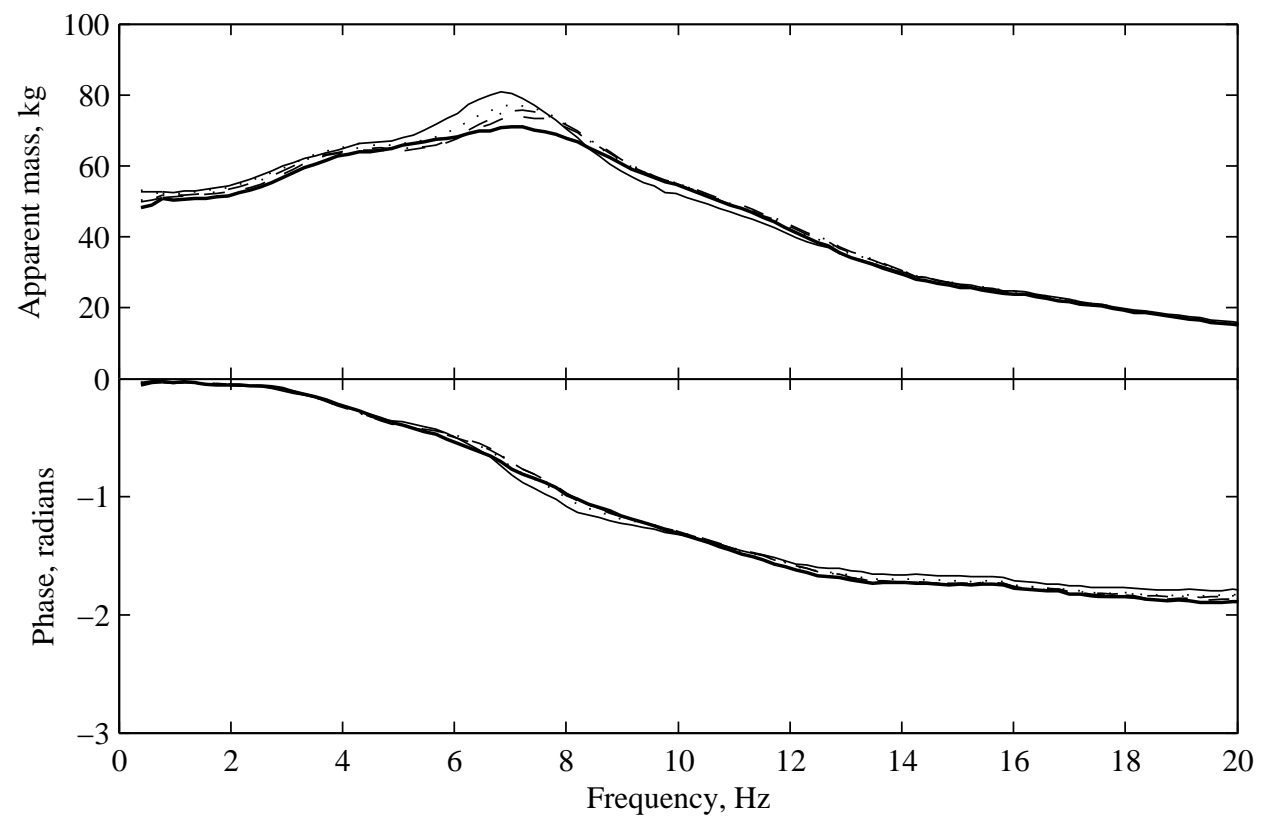

Fig. 6 Effect of force applied to the steering wheel on apparent mass (medians of 12 subjects with the hands at $\mathrm{S}_{\mathrm{H} 3}$ and the feet at $\left.\mathrm{F}_{44}\right): 0 \mathrm{~N}(-), 50 \mathrm{~N}() 100 \mathrm{~N}(-), 150 \mathrm{~N}(---)$ and $200 \mathrm{~N}(-)$ at $1.0 \mathrm{~ms}^{-2}$ r.m.s. 


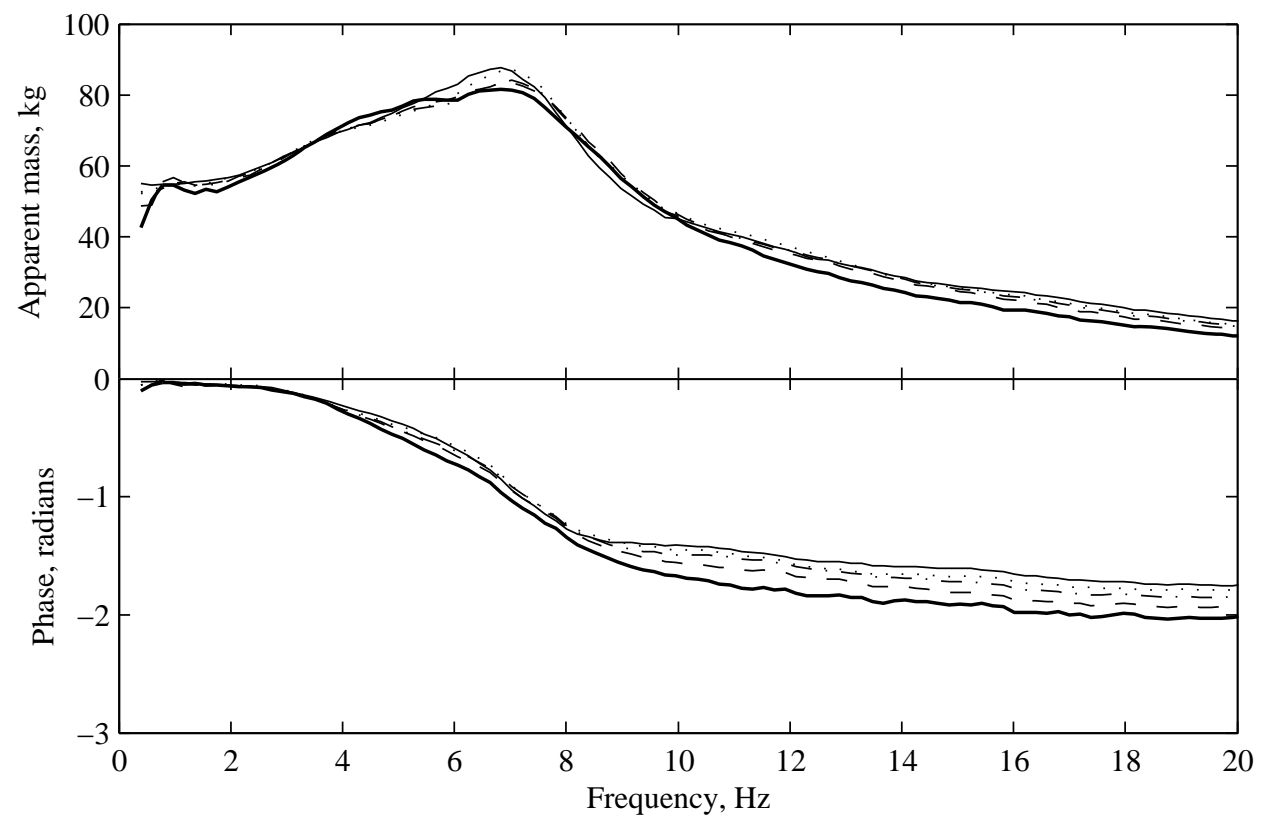

Fig. 7 Effect of force applied to the footrest on apparent mass (medians of 12 subjects with the hands in lap and footrest at $\left.\mathrm{F}_{\mathrm{H} 4}\right): 0 \mathrm{~N}(-), 50 \mathrm{~N}(), 100 \mathrm{~N}(-), 150 \mathrm{~N}(---)$ and $200 \mathrm{~N}(-)$. 


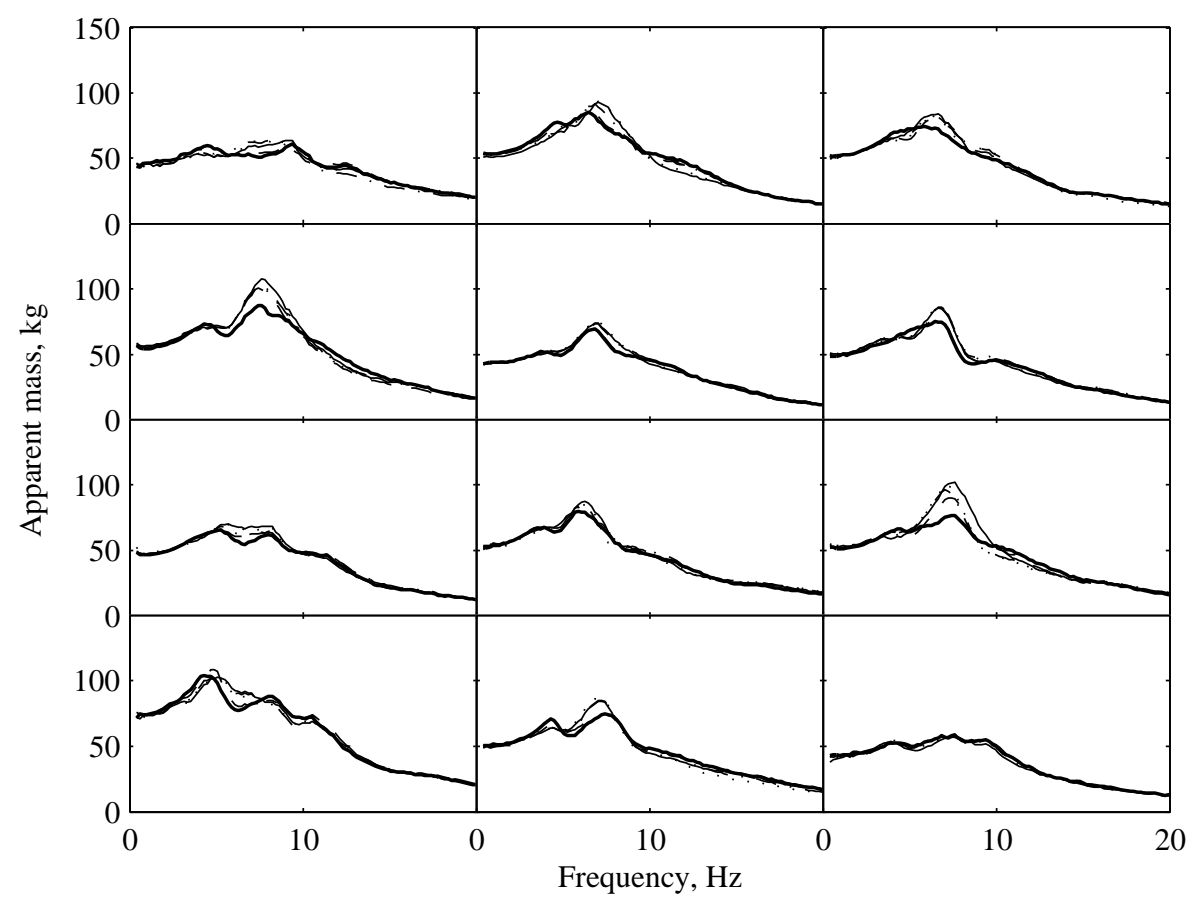

Fig. 8 Individual apparent masses for 12 subjects with the steering wheel at five different horizontal positions (steering wheel at vertical position $\mathrm{S}_{\mathrm{v} 3}$ and footrest at $\left.\mathrm{FH}_{4}\right): \mathrm{S}_{\mathrm{H} 1}(-), \mathrm{S}_{\mathrm{H} 2}(), \mathrm{S}_{\mathrm{H} 3}(-)$, $\mathrm{S}_{\mathrm{H} 4}(---$ ) and $\mathrm{S}_{\mathrm{H} 5}(-)$ at $1.0 \mathrm{~ms}^{-2}$ r.m.s. 